\title{
CORRIGENDUM
}

\section{MMP7-mediated cleavage of nucleolin at Asp255 induces MMP9 expression to promote tumor malignancy}

T-I Hsu, S-C Lin, P-S Lu, W-C Chang, C-Y Hung, Y-M Yeh, W-C Su, P-C Liao and J-J Hung

Oncogene (2017) 36, 875-876; doi:10.1038/onc.2016.274; published online 1 August 2016

Correction to: Oncogene (2015) 34, 826-837; doi: 10.1038/onc. 2014.22; published online 17 March 2014

The authors were recently made aware of some confusion regarding Figure 4 in this publication.

In Figure 4, the authors provide two groups images of $\mathrm{NCL}$ and MMP7 from the same mice but consecutive sections. However, the labeling has led some readers to incorrectly conclude that images of NCL and MMP7 are from two different mice. Please see a relabeled image and new figure legend for clarification.

The authors wish to apologize to the readers and publisher for any confusion. 
a

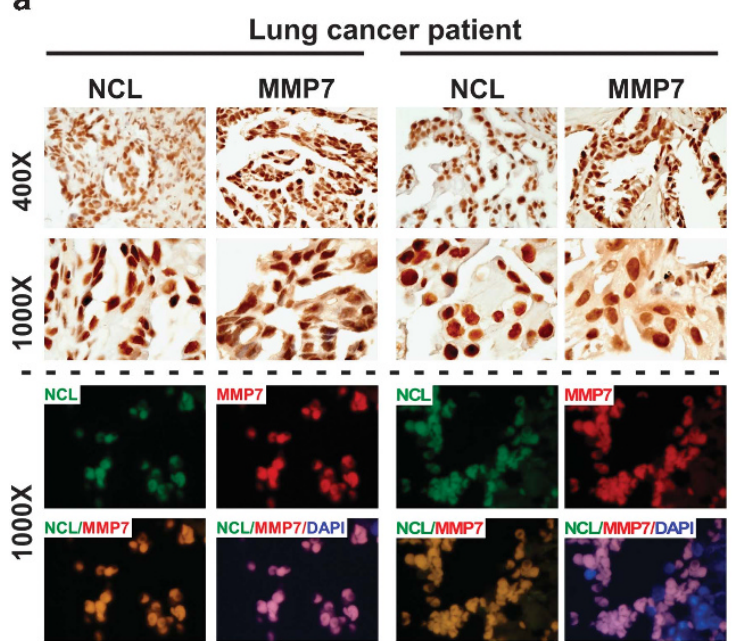

b

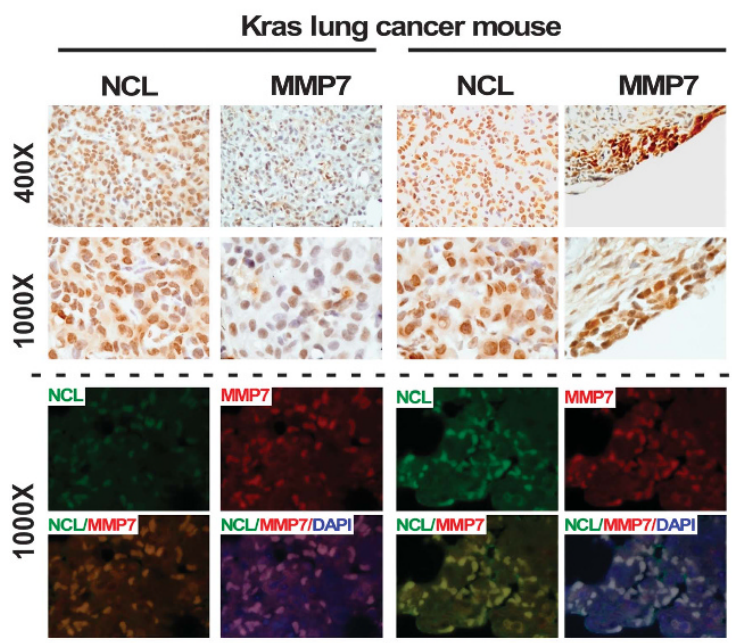

C

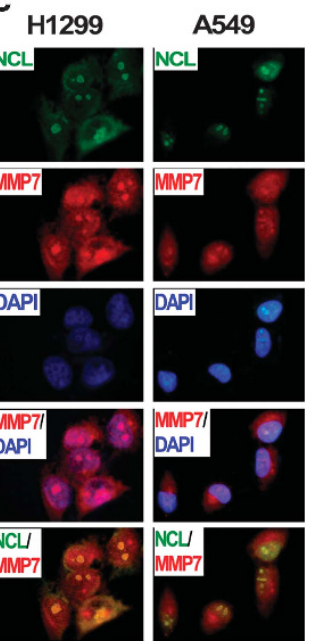

d $\mathbf{w}$ Cy $\mathrm{Nu}$
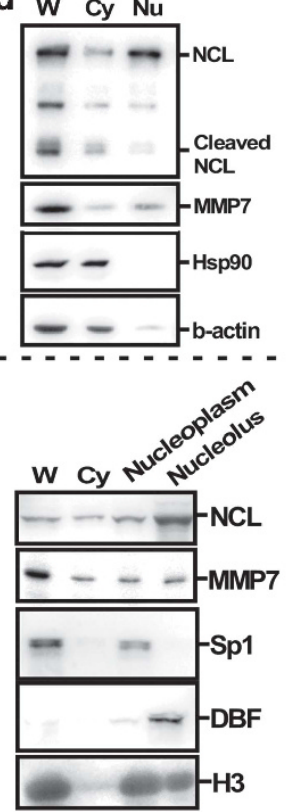

Figure 4. The distributions of NCL and MMP7 in lung cancer cells in vitro and in vivo. (a) The 5- $\mu$ m slices of paraffin-embedded specimens were prepared for IHC and immunoflurescent staining by using anti-c23 and anti-MMP7 antibodies. (b) NCL and MMP7 expression levels in lung tumor tissues of K-ras ${ }^{\mathrm{G}}{ }^{2 \mathrm{D}}$ lung cancer mice. Two consecutive sections were stained at different times to confirm indicated protein expression in the lung. (c) Fixed H1299 and A549 cells were immunofluorescently co-stained by antibodies targeting NCL and MMP7. (d) The whole cell (W), cytosolic (Cy), nuclear (Nu), nucleoplasmic and nucleolar fractions were prepared for western blotting. 